\title{
Case Report Xanthoma of Bone: A Case Report
}

\author{
Hasnae Guerrouj, Ayat Mouaden, and Nouzha BenRais \\ Nuclear Medicine Department, University of Mohammed V-Souissi, Rabat, Morocco \\ Correspondence should be addressed to Hasnae Guerrouj, guerroujh@yahoo.fr
}

Received 26 December 2011; Accepted 30 January 2012

Academic Editors: T. Konrad and H. Takeyama

Copyright ( $) 2012$ Hasnae Guerrouj et al. This is an open access article distributed under the Creative Commons Attribution License, which permits unrestricted use, distribution, and reproduction in any medium, provided the original work is properly cited.

Bone xanthoma is a rare disease due to the presence of cholesterol deposits in the bone. We report a case of a 56-yearold patient who was hospitalized in orthopedic department for fracture on the left humerus. Histological examination of bone biopsy performed at this site has objectified cholesterol deposits. Laboratory tests showed hypercholesterolemia with hypertriglyceridemia. The diagnosis of bone xanthoma was selected. The fracture was treated surgically. An initial bone scan revealed bone lesions localized especially at the humerus and femur. The patient was put under fenofibrate and statins. The evolution was marked by gradual regression of lesions in bone scans of control.

\section{Introduction}

Xanthoma is a benign lesion whose origin is abnormal deposition of cholesterol deposits on parts of the body other than blood vessels. This leads to an inflammatory cell infiltration. This lesion contains abundant foamy histiocytes most commonly occurring in superficial soft tissues such as skin, subcutis, or tendon sheaths. The involvement of deep skeletal structures, however, is rare. Most xanthomas occur in patients with hyperlipidemic disorders. We present a case of intraosseous xanthoma localized in long bones, review the literature, and demonstrate the value of bone scintigraphy in the management of this benign bone disease.

\section{Observation}

A 56-year-old male patient, without history of significant disease, has been hospitalized in the orthopedic department for fracture of the left humerus. X-ray showed clear images within bone. An initial HMDP-Tc99m bone scan revealed bone lesions localized especially at the humerus and femur (Figure 1). Histological examination of bone biopsy performed at the fracture site objectified cholesterol deposits. Laboratory tests showed hypercholesterolemia with hyper triglyceridemia. The diagnosis of bone xanthoma was selected. The fracture was treated surgically. The patient was put under $160 \mathrm{mg} /$ jour of fenofibrate and $40 \mathrm{mg} /$ jour of statin drug. The evolution was marked by gradual regression of lesions in bone scans of control. We did not notice any recurrence during four years of the followup.

\section{Discussion}

Bone xanthoma is a rare disorder due to the presence of cholesterol deposits in the bone. It is usually found in hyperlipidemia and hyperlipoproteinemia family. These are characterized by elevated levels of cholesterol that form deposits in soft tissue and bone $[1,2]$. These are also reported in nonhyperlipidemic states $[3,4]$. The most frequent location of bone xanthoma is the diaphysis of long bones, especially the tibia. Other locations may be particularly in the facial skeleton, mastoid air cells [5-7], and mandibular bone [8]. The skull can be affected (temporal [5-7] or frontal [9]) which may cause cerebellar compression.

The axial skeleton is not spared. A xanthoma case of sacrum [10] and calcaneus [11] has been described in the literature. Xanthoma of bone is characterized as a lytic lesion, often with cortical expansion or disruption [12]. $\mathrm{X}$-ray images show intraosseous clear images sometimes resulting in deformities of the bone. Bone scintigraphy allows for mapping of lesions and posttherapy followup. It highlights increased uptake of long bones diaphyses, skull, and some bones of the face. The diagnosis is histological. 


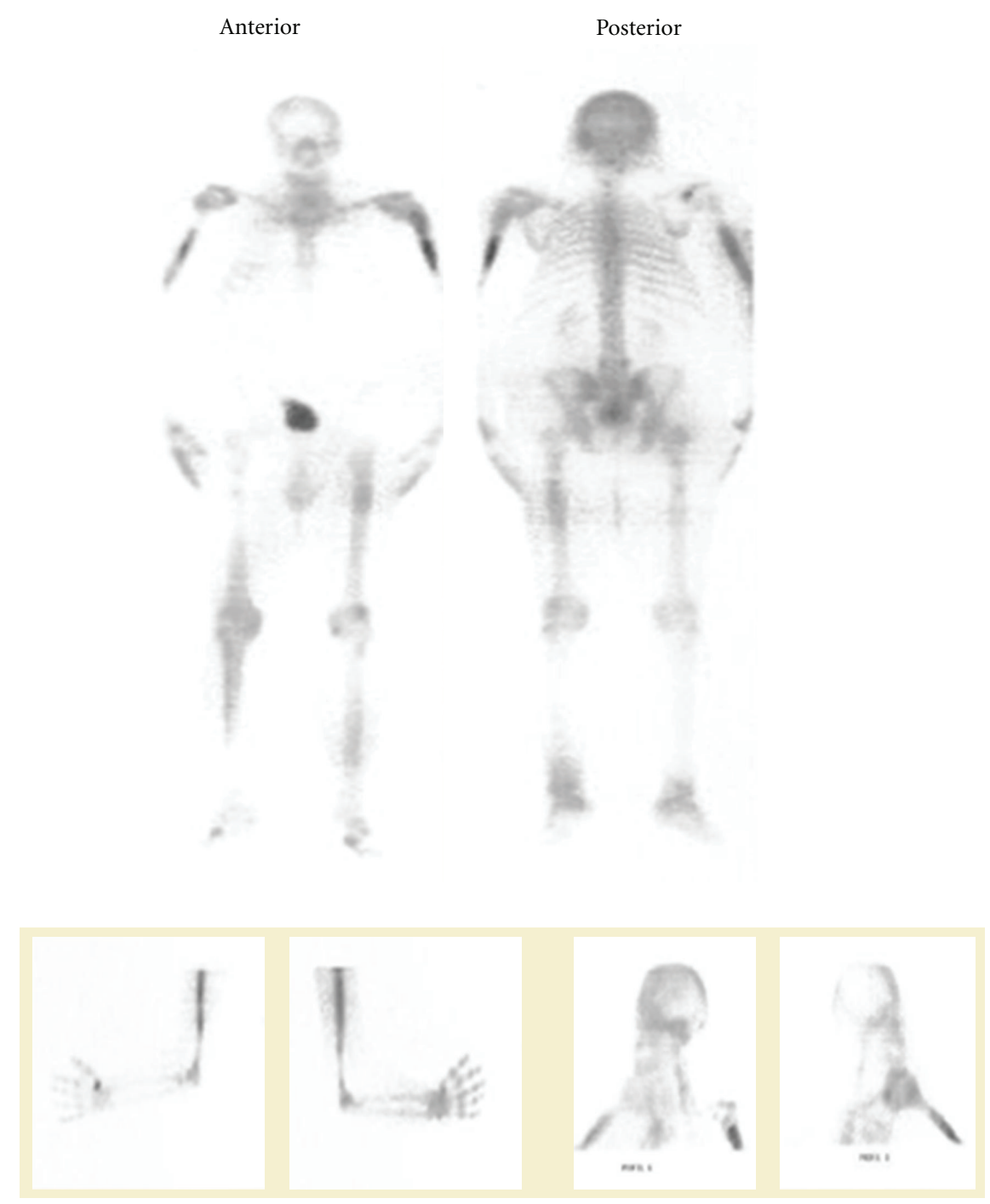

FIGURE 1: HMDP-Tc99m bone scan (anterior and posterior): increased uptake localised in diaphyses of humerus and femurs.

Other diagnoses must be ruled out such as histiocytosis X, Erdheim-Chester, and clear cell carcinoma metastasis. The treatment is medical and surgical.

\section{Conclusion}

Bone xanthoma is a benign disease whose prognosis is good even after partial excision. The role of bone scintigraphy is useful in the staging of the disease and in therapeutic monitoring.

\section{Conflict of Interests}

The authors declare that there is no conflict of interests.

\section{References}

[1] K. Yokoyama, N. Shinohara, and K. Wada, "Osseous xanthomatosis and a pathologic fracture in a patient with hyperlipidemia. A case report," Clinical Orthopaedics and Related Research, no. 236, pp. 307-310, 1988.
[2] D. Dallari, A. Marinelli, A. Pellacani et al., "Xanthoma of bone: first sign of hyperlipidemia type IIB: a case report," Clinical Orthopaedics and Related Research, no. 410, pp. 274-277, 2003.

[3] S. Boisgard, O. Bringer, B. Aufauvre et al., "Xanthome osseux sans désordre lipidique: À propos d'un cas et revue de la littérature," Revue du Rhumatisme, vol. 67, no. 1, pp. 83-86, 2000.

[4] A. Ayadi-Kaddour, M. Mlika, A. Marghli, T. Kilani, and F. E. Mezni, "Xanthoma of the rib without hyperlipoproteinemia," Respiratory Medicine CME, vol. 1, no. 1, pp. 40-42, 2008.

[5] C. Turk, B. Bilginer, K. Benli, K. Yavuz, A. Saglam, and I. M. Ziyal, "Bilateral temporal bone xanthomas in type II hypercholesterolemia," Turkish Neurosurgery, vol. 20, no. 4, pp. 533-535, 2010.

[6] K. A. Muthusamy, K. Azmi, P. Narayanan, R. Rajagopalan, N. A. Rahman, and V. Waran, "Bilateral temporal bone xanthoma: case report," Journal of Neurosurgery, vol. 108, no. 2, pp. 361-364, 2008.

[7] T. Kuroiwa, T. Ohta, and A. Tsutsumi, "Xanthoma of the temporal bone: case report," Neurosurgery, vol. 46, no. 4, pp. 996-998, 2000. 
[8] M. Marqués Mateo, M. Puche Torres, L. Miragall Alba, M. E. Iglesias Gimilio, and J. V. Pascual Gil, "Primary mandibular bone xanthoma. A case report," International Journal of Oral and Maxillofacial Surgery, vol. 33, no. 8, pp. 806-807, 2004.

[9] E. T. Elwood, T. G. Shahwan, N. Dajani, and J. D. Murray, "Isolated xanthoma of the frontal bone," Journal of Craniofacial Surgery, vol. 16, no. 3, pp. 391-394, 2005.

[10] G. S. Huang, C. W. Huang, C. H. Lee, J. A. M. Taylor, C. G. Lin, and C. Y. Chen, "Xanthoma of the sacrum," Skeletal Radiology, vol. 33, no. 11, pp. 674-678, 2004.

[11] U. Yalcinkaya and F. Oztop, "Xanthoma of the calcaneus associated with hyperlipoproteinemia [1]," Journal of the American Podiatric Medical Association, vol. 95, no. 6, pp. 602604, 2005.

[12] K. J. Alden, E. F. McCarthy, and K. L. Weber, "Xanthoma of bone: a report of three cases and review of the literature," The Iowa orthopaedic journal, vol. 28, pp. 58-64, 2008. 


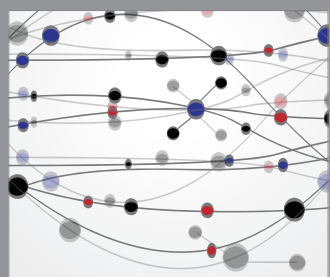

The Scientific World Journal
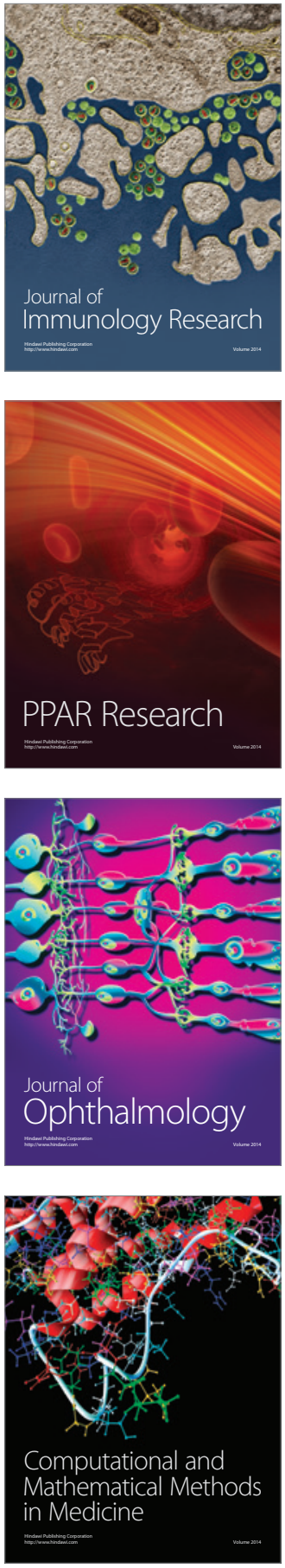

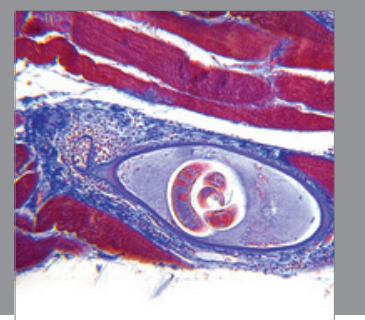

Gastroenterology

Research and Practice
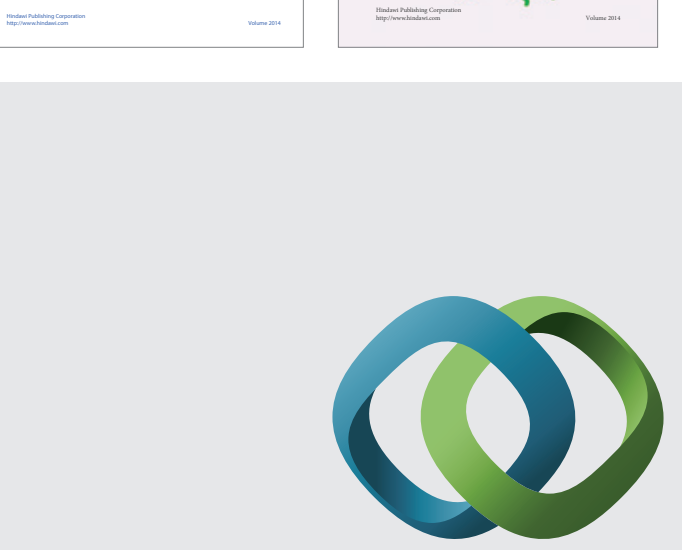

\section{Hindawi}

Submit your manuscripts at

http://www.hindawi.com
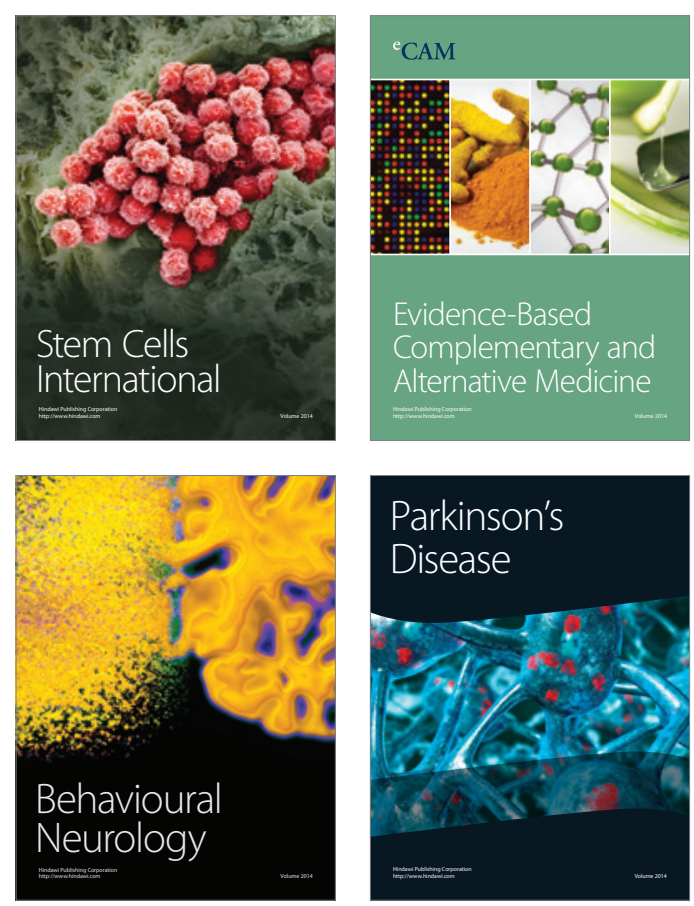

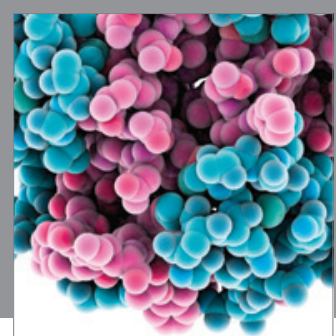

Journal of
Diabetes Research

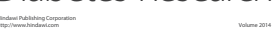

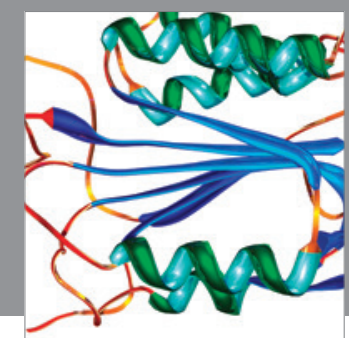

Disease Markers
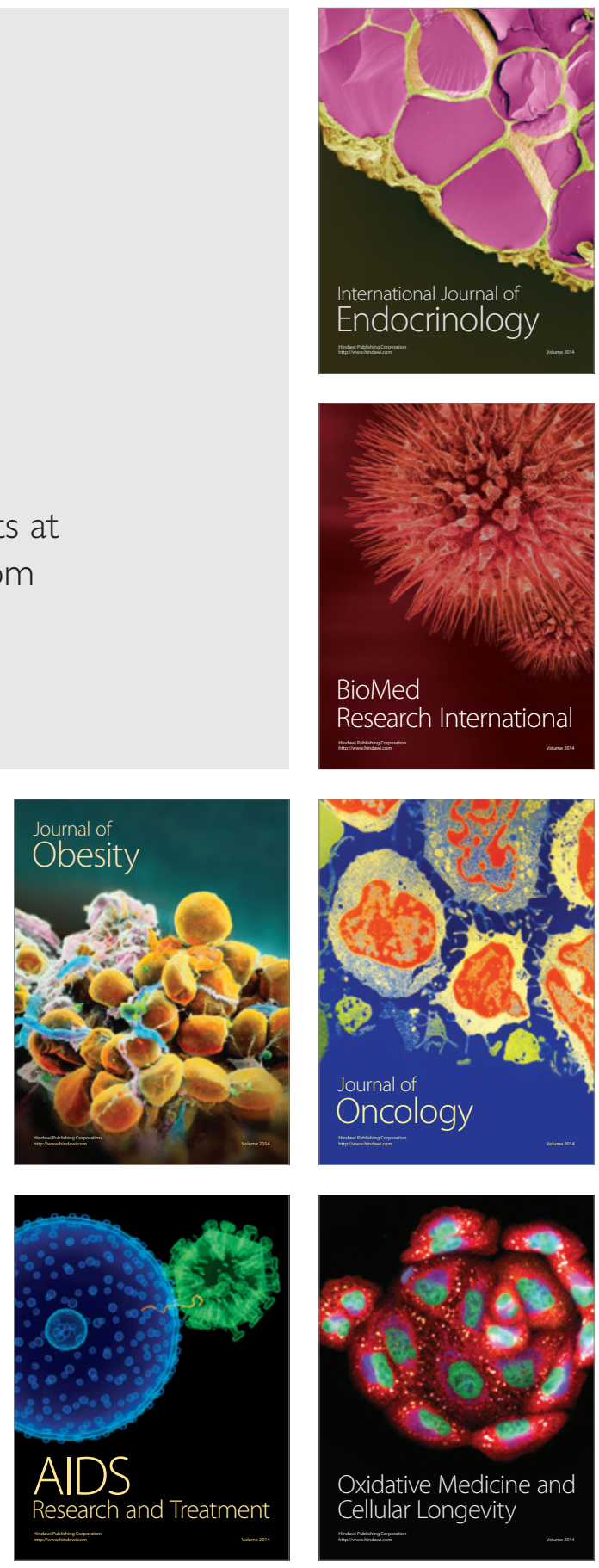